\title{
Surgical treatment of primary spontaneous pneumothorax with video-assisted thoracic surgery
}

\author{
J. Freixinet*, E. Canalis**, J.J. Rivas+, F. Rodriguez de Castro*, J. Torres ${ }^{+}$, \\ J.M. Gimferrer**, J. Sanchez-Lloret**
}

Surgical treatment of primary spontaneous pneumothorax with video-assisted thoracic surgery. J. Freixinet, E. Canalis, J.J. Rivas, F. Rodriguez de Castro, J. Torres, J.M. Gimferrer, J. Sanchez-Lloret. CERS Journals Ltd 1997.

ABSTRACT: We report the results of our experience using video-assisted thoracoscopic surgery (VATS) to treat primary spontaneous pneumothorax (PSP) from January 1992 until December 1994 in a multicentered co-operative study.

A total of 132 patients (110 males and 22 females, aged 13-38 yrs, mean age 26 yrs) were treated by VATS to deal with the PSP that they presented with. A standard VATS technique was used. Apical bullae were always removed, and mechanical pleural abrasion was performed, leaving a pleural drainage tube.

In two cases (1.5\%), a switch to thoracotomy was necessary. In eight cases (6\%), air leakage persisted for 5 days after surgery, which resolved with pleural drainage. There were eight postoperative relapses $(6 \%)$, which were treated with pleural drainage $(n=4)$, VATS $(n=3)$ or axillar thoracotomy $(n=1)$. The average postoperative stay was 5.6 days (range $2-15$ days).

We conclude that video-assisted thoracoscopic surgery is a viable alternative for the treatment of primary spontaneous pneumothorax. There is, however, a high relapse rate, and in a number of cases air leakage persists in the postoperative period.

Eur Respir J 1997; 10: 409-411.

*Thoracic Surgery Service, University Hospital Ntra. Sra. del Pino, of Las Palmas de Gran Canaria, Canary Islands, Spain. Clinico y Provincial, Barcelona, Spain. ${ }^{+}$Dept of Thoracic Surgery, Juan Canalejo, La Coruña, Spain.

Correspondence: J. Freixinet

Thoracic Surgery Service

University Hospital Ntra, Sra, del Pino

C/Angel Guimerá 93

35005 Las Palmas de Gran Canaria

Canary Islands

Spain

Keywords: Pneumothorax primary spontaneous pneumothorax spontaneous pneumothorax thoracoscopy

video-assisted thoracoscopy

Received: February 11996

Accepted after revision October 251996

Primary spontaneous pneumothorax (PSP) is a benign process, but persistent air leaks or recurrence make surgical intervention necessary in $30-40 \%$ of cases. PSP has come to be treated in the classic form, through axillar thoracotomy; the results published have been good, with a minimum rate of relapse and morbidity [1-4]. Recent developments in video-assisted thoracoscopic surgery (VATS) allowed a change in surgical technique, reducing surgical intervention. In order to evaluate VATS technique in PSP we initiated a multicentered study covering a period of $3 \mathrm{yrs}$.

\section{Materials and methods}

Between January 1992 and December 1994, a co-operative multicentered study was carried out by the Thoracic Surgery departments of three teaching hospitals. A total of 132 patients affected with PSP were treated by VATS. The indications for surgery for PSP were as follows: 1) persistent air leakage of more than 7 days after pleural drainage at the first episode of PSP $(n=24)$; and 2) ipsilateral relapse in a case of PSP previously treated by pleural drainage $(n=108)$. Cases of spontaneous pneumothorax, in which the patient had no primary pulmonary disease, were considered to have PSP.

Patients treated through axillar thoracotomy during this same period of time were excluded from the study, as were patients with secondary pneumothorax, those more than $40 \mathrm{yrs}$ of age (although not suspected of hav- ing basic pulmonary disease), and those of traumatic origin.

The technique used was the same in all cases. It was carried out using general anaesthesia with a doublelumen endobronchial tube. Three incisions were made in order to introduce the optical equipment, the thoracic endoscopy instruments, and the endosutures. A removal of (generally apical) bullae or dystrophic complexes responsible for the episodes of pneumothorax was always performed. In cases of air leakage, air leak tests were performed with insufflation under saline installation in order to localize them. The intervention was completed with mechanical pleural abrasion. In all cases, a pleural drainage tube was left in after ensuring that there was no more leakage.

Thoracoscopic findings were classified, according to the criteria described by VANDERSCHUEREN [5] into four categories: category I, patients without anomalies under thoracoscopy; category II, patients with pleural adhesions; category III, patients with multiple blebs in the visceral pleura; and category IV, patients with distinct bullous lesions, blebs or adherences. For comparison between groups, the Chi-squared statistical test was used. A p-value less than 0.05 was considered significant.

Postoperative control was performed in the recovery room, and in 4-6 h the patients were returned to their wards. Conventional analgesics and nonsteroidal antiinflammatory drugs were always administered. All the patients were reviewed in the out-patient clinic 1 month 
after discharge, and then every 6 months to assess their general health and return to their normal routine.

\section{Results}

The ages of the patients ranged 13-38 yrs, with a median age of 26 yrs. One hundred and ten cases were males $(83 \%)$. During the period of study, a total of 234 procedures were carried out using VATS of which the treatment of PSP represented $47 \%$.

There were no significant intraoperative complications in any of the cases, although in two (1.5\%) it became necessary to switch from VATS to axillar thoracotomy due to the presence of substantial vascular adhesions, which impeded a correct pulmonary dissection. Specimens were always obtained from the apex of the lung supposedly responsible for the episodes of pneumothorax. In 36 of the cases considered, lesions classified under category II were found; in 71 category III; and in 25 category IV. In all of the cases, some type of lesion that could potentially have been responsible for the episodes of pneumothorax was found, perhaps due to the magnification of the images in VATS. For that reason, there were no cases I considered under category. In order to excise these pathological pulmonary segments, an average of 2.5 charges of mechanical endoscopic sutures were utilized, with a minimum of one and a maximum of eight.

There were no major complications of VATS (table 1). In eight cases $(6 \%)$, there was persistent air leakage for more than 7 days, which resolved with further pleural drainage. The postoperative admission ranged 2-15 days, with an average of 5.6 days. There were eight postoperative relapses $(6 \%)$ during the first month after an intervention which were treated with drainage $(n=4)$, $\operatorname{VATS}(n=3)$, or axillar thoracotomy $(n=1)$, depending on the size of the pneumothorax and the degree of pulmonary collapse. All episodes of persistent air leakage or relapse occurred in patients who underwent a resection of blebs (five persistent air leakages and six relapses in category III; $\mathrm{p}<0.05 v s$ other categories). No relationship was found between age and relapse (the average age of the group with persistent air leakage was $25 \mathrm{yrs})$. In the four cases with relapses that were treated with VATS or thoracotomy, an air leak was always found. In three cases, it resulted from an incompletely resected bleb, and in one case from a suture made during the first operation. In all four cases, there were partial pleuropulmonary adherences that did not impede pulmonary collapse. In all of these cases, the final outcome was satisfactory.

No systemic appraisal was established for analgesia, but in general terms it was felt satisfactory, since it was not necessary to use powerful analgesic drugs. There

Table 1. - Rates of persistent air leakage and relapse in 132 patients after VATS

\begin{tabular}{lll}
\hline Persistent air leakage & 8 & $(6)$ \\
Postoperative relapse & 8 & $(6)$ \\
Treated with drainage & 4 & $(3)$ \\
Treated with VATS & 3 & $(2)$ \\
Treated with axillar thoracotomy & 1 & $(1)$ \\
\hline
\end{tabular}

Values are presented as absolute number, and percentage in parenthesis. VATS: video-assisted thoracoscopic surgery. was no persistent thoracic pain or intercostal neuralgia at the points of incision. All of the patients resumed their normal routines without limitations within the first month after discharge. In the succeeding 10 months to 3 yrs no relapses occurred.

\section{Discussion}

The therapeutic strategy in PSP is commonly based on the utilization of pleural drainage for the first episode. With this treatment, relapses and persistence of pneumothorax occur in $30-40 \%$ of the cases. The treatment of such recurrent or persistent PSP has been classically surgical, through axillar thoracotomy. This type of surgical approach allows treatment of the primary cause of pneumothorax (mainly subpleural bullae or blebs, and localized fibrotic complexes, generally apical) and a proper mechanical abrasion [1-4]. Axillar thoracotomy has excellent results with respect to relapse and morbidity, and our groups used it until the introduction of VATS [2]. The rate of relapse with axillar thoracotomy in the treatment of PSP is $1 \%$, a figure outlined in a classic study by DesLAURIERs et al. [6], and there are still groups that consider axillar thoracotomy as the treatment of choice for PSP [7]. As an alternative approach, posterolateral thoracotomy has also been reported, but it is more often used in the treatment of secondary spontaneous pneumothorax (SSP) [8].

Surgical treatment of PSP through thoracoscopy has been described by various authors [9], utilizing diverse methods, such as the introduction of chemical substances to induce pleurodesis, principally talc and tetracycline [10-16]. Talc, as a method of pleurodesis, has been used much more extensively in the treatment of malignant pleural effusions. Its use in pneumothorax has been associated with good results, although the use of this technique is more often reported in patients with SSP than those with PSP. Overall, good results have been obtained in around 90\% of cases [10-12]. When the use of talc through thoracoscopy is directly compared to resection of bullae, the latter proves superior. In pleurodesis using tetracycline, a 6-9\% relapse rate has been described. A comparative study of PSP both through pleurodesis with tetracycline and abrasion through thoracotomy showed a greater relapse rate of $8 \%$ in the former [13]. Other means of pleurodesis used were biological glues [17] and laser [18]. We have continued to use the same surgical approach as used in classical surgery, but we have adapted it to VATS.

The main advantage of this treatment with respect to conventional surgery is the production of minor surgical trauma. The majority of studies regarding the treatment of pneumothorax through VATS usually make reference to spontaneous pneumothorax in general, without distinction between primary and secondary pneumothorax. Up to now, the data that have been published give figures that do not vary much, usually oscillating between 3 and $3.8 \%$ with respect to complications, and 0 to $7 \%$ with respect to relapses, with an average hospital stay of about 5 days [19-23]. As far as the treatment of PSP is concerned, similar results to our study have been published, with complication rates of $8 \%$ and relapses of 3\% [24]. Studies comparing axillar thoracotomy and VATS in the treatment of PSP concluded 
that the latter is superior with respect to its better control of postoperative pain, better respiratory functioning, and a shorter average hospital stay [25, 26].

As a result of our experience with both techniques, we feel that, although the average hospital stay does not appear to have been significantly reduced, VATS represents an advance with respect to patient aesthetics and less aggressive invasion; it has therefore become a valid technical option in the surgical treatment of PSP. The marked impact of VATS in the treatment both of PSP and SSP should be noted [27]. In our overall experience with VATS, the treatment of PSP accounted for $47 \%$ of the procedures carried out by us. In the multicentered study of the Video Assisted Thoracic Group in the United States [28] it represented 9\%.

There are some drawbacks, such as the appreciable percentage of persistent postoperative air leakage that has been described previously for VATS, and the occasional necessity to convert to thoracotomy. The occurrence of postoperative relapses is clearly a drawback [16]. In our study $6 \%$ relapse occurred, which is clearly greater than following standard surgery. It is interesting to note that all of the relapses occurred soon after surgery

We conclude that video-assisted thoracoscopic surgery is, currently, a valuable alternative for the treatment of primary spontaneous pneumothorax in those patients where multiple pleuropulmonary adhesions are not suspected. Its main advantage over axillar thoracotomy is that it represents less invasive surgery, resulting in smaller scars. The rate of postoperative relapse and some cases of persistent air leakage are drawbacks that should be evaluated when more experience has been accumulated. Other possible advantages of classical surgery, such as better analgesia and reduction of postoperative functional repercussions, should also be evaluated in the future.

\section{References}

1. Loscertales Abril J, Ayarra Jarné J, García Díaz J, Arenas Linares C, Rico Alvarez A. Neumotórax espontáneo. Madrid, Editorial Elba, 1988.

2. Freixinet J, López L, Rodríguez de Castro F, Hussein M, Quevedo S, Hermosa MJ. Neumotórax espontáneo primario: estudio retrospectivo sobre 495 casos. Arch Bronconeumol 1995; 31: 276-279.

3. Teixidor J, Estrada G, Solé J, et al. Neumotórax espontáneo: a propósito de 2,507 casos. Arch Bronconeumol 1994; 30: 131-135.

4. Zapatero J Peñalver R, Lego J, et al. Tratamiento quirúrgico del neumotórax espontáneo primario: revisión de 326 casos. Arch Bronchoneumol 1990; 6: 65-67.

5. Vanderschueren RGJRA. The role of thoracoscopy in the evaluation and management of pneumothorax. Lung 1990; 168 (Suppl.): 1122-1125.

6. Deslauriers J, Beaulieu M, Després JP, Lemieux M, Leblanc J, Desmeules M. Transaxillary pleurectomy for treatment of spontaneous pneumothorax. Ann Thorac Surg 1980; 30: 569-575.

7. Simansky DA, Yellin A. Pleural abrasion via axillary thoracotomy in the era of video-assisted thoracic surgery. Thorax 1994; 49: 922-923.

8. Waller DA, Forty J, Morritt GN. Video-assisted thoracoscopic surgery versus thoracotomy for spontaneous pneumothorax. Ann Thorac Surg 1994; 58: 372-376.
9. Rivas JJ, Torres J. Thoracoscopy and spontaneous pneumothorax. Ann Thorac Surg 1993; 55: 811.

10. Van de Brekel JA, Durkens VA, Vanderschueren RG. Pneumothorax: results of thoracoscopy and pleurodesis with talc poudrage and thoracotomy. Chest 1993; 103: 345-347.

11. Weissberg D, Ben-Zeev I. Talc pleurodesis: experience with 360 patients. J Thorac Cardiovasc Surg 1993; 106: 689-695.

12. Milanez JR, Vargas FS, Filomeno LT, Fernández A, Jatene A, Light RW. Intrapleural talc for the prevention of recurrent pneumothorax. Chest 1994; 106: 1162-1165.

13. Krasnik M, Stimpel H, Halkier E. Treatment of primary spontaneous pneumothorax with intrapleural tetracycline instillation or thoracotomy: follow-up of management program. Scand J Thorac Cardiovasc Surg 1993; 27: 49-51.

14. Olsen PS, Andersen HO. Long-term results after tetracycline pleurodesis in spontaneous pneumothorax. Ann Thorac Surg 1992; 53: 1015-1017.

15. Waterworth PD, Kallis P, Townsend ER, Fountain SW. Thoracoscopic bullectomy and tetracycline pleurodesis for the treatment of spontaneous pneumothorax. Respir Med 1995; 89: 563-566.

16. Alfageme I, Moreno L, Huertas C, Vargas A, Hernández J, Beiztegui A. Spontaneous pneumothorax: long-term results with tetracycline pleurodesis. Chest 1994; 106: 347-350.

17. Hansen MK, Kruse-Andersen S, Watt-Boolsen S, Andersen K. Spontaneous pneumothorax and fibrin glue sealant during thoracoscopy. Eur J Cardiothorac Surg 1989; 3: 512-514.

18. Wakabayashi A, Brenner M, Wilson AF, Tadir Y, Berns M. Thoracoscopic treatment of spontaneous pneumothorax using carbon dioxide laser. Ann Thorac Surg 1990; 50: 786-790.

19. Janssen JP, Van Mourik J, Cuesta-Valentín M, Sutedja G, Gingengack K, Postmus PE. Treatment of patients with spontaneous pneumothorax during videothoracoscopy. Eur Respir J 1994; 7: 1281-1284.

20. Takeno Y. Thoracoscopic treatment of spontaneous pneumothorax. Ann Thorac Surg 1993; 56: 688-690.

21 Yamaguchi A, Shinonaga M, Tatebe S, Souma T, Tsuchida M, Saito A. Thoracoscopic stapled bullectomy supported by suturing. Ann Thorac Surg 1993; 56: 691-693.

22. Cannon WB, Vierra MA, Cannon A. Thoracoscopy for spontaneous pneumothorax. Ann Thorac Surg 1993; 56: 686-687.

23. Liu HP, Lin PJ, Hsieh MJ, Chang JP, Chang CH. Thoracoscopic surgery as a routine procedure for spontaneous pneumothorax: results from 82 patients. Chest 1995; 107: 559-562.

24. Yim AP, Ho JK. One hundred consecutive cases of video-assisted thoracoscopic surgery for primary spontaneous pneumothorax. Surg Endosc 1995; 9: 332-336.

25. Inderbitzi RG, Leiser A, Furrer M, Althaus U. Three years experience in video-assisted thoracoscopic surgery for spontaneous pneumothorax. I Thorac Cardiovasc Surg 1994; 107: 1410-1415.

26. Hazelrigg SR, Landreneau RJ, Mack M, et al. Thoracoscopic stapled resection for spontaneous pneumothorax. J Thorac Cardiovasc Surg 1993; 105: 389-392.

27. Waller DA, Forty J, Soni AK, Conacher ID, Morritt GN. Videothoracoscopic operation for secondary spontaneous pneumothorax. Ann Thorac Surg 1994; 57: 1612-1615.

28. Hazelrigg SR, Nunchuck SK, LoCicero J. Video-Assisted Thoracic Surgery Study Group data. Ann Thorac Surg 1993; 56: 1039-1044. 